\title{
Novas abordagens experimentais para o combate de infecções causadas por Staphylococcus aureus.
}

\author{
New experimental approaches to combat infections caused by Staphylococcus \\ aureus.
}

Deivid Martins Santos ${ }^{1}$, Alexsander Rodrigues Carvalho Junior ${ }^{1}$, Brenda da Silva Cutrim ${ }^{1}$, Patrícia Vieira de Oliveira ${ }^{1}$, Warlison Felipe de Silva Saminez ${ }^{1}$, Luís Cláudio Nascimento da Silva ${ }^{1}$.

\begin{abstract}
Resumo: Staphylococcus aureus tem sido destacado devido sua capacidade de expressar uma variedade de fatores de virulência e adquirir resistência aos agentes antimicrobianos, resultando em um largo espectro de doenças que são cada vez mais difíceis de serem tratadas. Além disso, um número cada vez maior de linhagens de $S$. aureus tem demonstrado resistência aos agentes antimicrobianos; por esta razão, $S$. aureus resistente à meticilina (MRSA) e $S$. aureus multirresistente (MDRSA) têm sido reconhecidos como as principais causas de infecções hospitalares. O objetivo deste trabalho foi apresentar conceitos relacionados às estratégias inovadoras desenvolvidas para combater infecções causadas por $S$. aureus. A obtenção dos dados bibliográficos foi realizada através da pesquisa em bancos de dados (Google scholar, NCBI - National Center for Biotechnologylnformation, PubMed e Scielo - ScientificElectronic Library Online). Novas estratégias para o combate de infecções causadas por $S$. aureus estão sendo desenvolvidas, com ênfase na (i) redução da resistência a antibióticos, (ii) inibição de fatores de virulência do patógeno (produção de coagulases, biofilme, toxinas e/ou estafiloxantina), (iii) ou no aumento da resposta imune do hospedeiro. O estudo retratou sobre a importância sobre o desenvolvimento e implantação de novas terapias antivirulência e imunomoduladoras como alternativa terapeutica e sua relevância na descoberta e aplicação de novas drogas.
\end{abstract}

Palavras-chave: Anti-coagulantes; Imunomoduladores; Antimicrobianos.

\begin{abstract}
Staphylococcus aureus has been highlighted because of its ability to express a variety of virulence factors and acquire resistance to antimicrobial agents, resulting in a broad spectrum of diseases that are increasingly difficult to treat. In addition, an increasing number of strains of $S$. aureus have demonstrated resistance to antimicrobial agents; for this reason, methicillin-resistant $S$. aureus (MRSA) and multiresistant $S$. aureus (MDRSA) have been recognized as the leading causes of nosocomial infections. The objective of this work was to present concepts related to the innovative strategies developed to fight infections caused by $S$. aureus. The bibliographic data was obtained through the database search (Google scholar, NCBI - National Center for Biotechnology Information, PubMed and Scielo - Scientific Electronic Library Online). New strategies to combat S. aureus infections are being developed, with emphasis on (i) reducing resistance to antibiotics, (ii) inhibiting pathogen virulence factors (production of coagulases, biofilms, toxins and / or staphyloxanthin ), (iii) or enhancement of host immune response. The study portrayed the importance on the development and implantation of new antiviral and immunomodulatory therapies as a therapeutic alternative and its relevance in the discovery and application of new drugs.
\end{abstract}

Keywords: Anti-coagulants; Immunomodulators; Antimicrobials.

\footnotetext{
${ }^{1}$ Laboratório de Imunologia das Doenças Infecciosas e Parasitárias, Universidade CEUMA, São Luís, Maranhão.
} 


\section{Introdução}

Doenças infecciosas ainda representam uma importante causa de morbidade e mortalidade entre seres humanos, especialmente nos países em desenvolvimento como o Brasil. Sem dúvida, a descoberta dos antibióticos na década de 1930 revolucionou a medicina e mudou 0 tratamento de doenças infecciosas, resultando em um aumento dramático na expectativa e qualidade de vida da humanidade. No entanto, desde que essas drogas foram introduzidas, a resistência microbiana evoluiu e se espalhou muito rapidamente ${ }^{1}$.

A aquisição de resistência microbiana aos antibióticos pode ocorrer através de mutações e a aquisição de plasmídeos $\mathrm{R}$ por diferentes mecanismos químicos, podendo também produzir enzimas que modificam a parte ativa da molécula do antibacteriano, tornando-o praticamente inativo, ou ainda, sintetizar novas enzimas que não sofrem a ação do antibacteriano e que possuem a mesma atividade metabólica das enzimas que são inativadas pelo mesmo. Mecanismos como a diminuição da permeabilidade da célula bacteriana, alterações de moléculas onde se aderem os antibacterianos, e expulsão do antibacteriano do interior da célula também conferem resistência às drogas antimicrobianas ${ }^{2,3}$.

A resistência bacteriana pode ser também disseminada pela introdução de microrganismos resistentes em uma população susceptível, por um paciente ou objeto inanimado. Como exemplo, pode-se citar a introdução em ambientes hospitalares de bactérias resistentes, as quais são transferidas aos pacientes em solução iodófora ou sabões previamente contaminados para a higienização das mãos. Assim, bactérias podem ganhar mobilidade e acessibilidade aos seres humanos por meio das mãos, roupas dos profissionais de saúde, por instrumentação (ou procedimentos) ou mesmo através da comida. Nesta última possibilidade, há referência do uso de antibióticos na agricultura (avoparcina), como suplementação alimentar animal, contribuindo para o desenvolvimento de resistência e favorecendo a disseminação destas sob diversas formas ${ }^{4}$.

Um agente etiológico importante associado a infecções adquiridas, tanto na comunidade como em hospitais, e que se tornou um paradigma das infecções bacterianas é Staphylococcus aureus. Considerado um dos principais patógenos humanos, destaca-se por incidência em casos de infecções tanto em indivíduos imunocomprometidos quanto em hígidos, devido a sua fácil disseminação intra-hospitalar associada à resistência aos antibióticos 5 . A frequência de $S$. aureus resistente à oxacilina (meticilina) varia conforme a região ou o hospital analisado. A título de exemplo, na cidade do Rio de Janeiro, no ano de 1998, a resistência à oxacilina foi de $27 \%$ entre amostras de $S$. aureus isoladas em um hospital (sem serviço de emergência), enquanto em outro hospital (com serviço de emergência) atingiu 58\%. Felizmente, esses microrganismos ainda são sensíveis à oxacilina e às cefalosporinas da primeira geração na maioria dos isolados do meio extra-hospitalar no Brasil, o que possibilita o uso destes antimicrobianos nas infecções estafilocócicas comunitárias ${ }^{6}$.

Portanto, existe uma necessidade constante de desenvolver novas abordagens e estratégias para

\footnotetext{
${ }^{1}$ Laboratório de Imunologia das Doenças Infecciosas e Parasitárias, Universidade CEUMA, São Luís,
} Maranhão. 
combater infecções causadas por esta bactéria, tais como: a descoberta de novo alvos antimicrobianos; procura por novos compostos (agentes antimicrobianos, moduladores de resistência, inibidores do sensor de quorum, etc.); e novas abordagens terapêuticas (anti-virulência e imunomoduladoras). Recentemente, tem sido demonstrado 0 papel desempenhado pelos mecanismos de coagulação no combate a sepse e na modulação da resposta imune. Com isso, agentes capazes de modular beneficamente a resposta imune do hospedeiro e limitar o excesso de coagulação têm sido apontados como promissores para 0 tratamento de infecções microbianas ${ }^{7,8}$.

Deste modo, este trabalho objetivou explorar o uso de novas estratégias para 0 combate de infecções causadas por $S$. aureus com ênfase na (i) redução da resistência a antibióticos, (ii) inibição de fatores de virulência do patógeno (produção de coagulases, biofilme, toxinas e/ou estafiloxantina), (iii) ou no aumento da resposta imune do hospedeiro. Os dados e informações bibliográficas foram obtidos em bancos de dados como: Google Scholar, NCBI (National Center for Biotechnology Information), PubMed e Scielo (Scientific Electronic Library Online).

\section{Desenvolvimento}

\section{Patogenicidade e virulência de Staphylococcus aureus}

Staphylococcus aureus é
considerado um dos principais
causadores de infecções associadas
com a assistência à saúde e a
comunidade, tal característica é devido
ao fato desse patógeno apresentar
diversos fatores de virulência que o
conferem um alto grau de

patogenicidade ${ }^{9}$. Sendo assim, $S$. aureus produz muitas toxinas, incluindo as cinco citolíticas ou que danificam a membrana (alfa, beta, delta, gama e leucocidina Panton-Valentine [PVL]) que foram descritas como hemolisinas, mas este é um termo impróprio, uma vez que a atividade das quatro primeiras toxinas não é restrita apenas às hemácias e a PVL é incapaz de causar lise em eritrócitos. As citotoxinas podem causar lise em neutrófilos, o que resulta na liberação de enzimas lisossômicas que, subsequentemente, danificam os tecidos circunjacentes. A PVL tem sido relacionada às infecções pulmonares e cutâneas graves ${ }^{10}$. Sendo assim, a produção de hemolisinas determina a patogenicidade de diversos agentes bacterianos, uma vez que ao degradar os tecidos do hospedeiro permitem a invasão e disseminação, além da evasão à resposta imune ${ }^{11}$.

Dentre esses fatores existe a produção de estafiloxantina, um pigmento caratenóide produzido pelo $S$. aureus, sendo responsável por sua cor amarelada e considerado como um fator de virulência que contribui para invasão do patógeno perante o sistema imunológico. Estudos mostraram que a deleção do gene que codifica a estafiloxantina resulta na diminuição da virulência deste patógeno, da mesma forma que bactérias transformadas para produzir maior quantidade do pigmento mostraram maior patogenicidade, demonstrando que esse caratenóide é necessário para promover a virulência bacteriana ${ }^{12}$. Também se destaca pela produção de biofilme, contribuindo para sua patogenicidade e limitando a eficácia da terapia antimicrobiana. Com isso, presença de um biofilme limita a eficiência da terapêutica antimicrobiana para o ponto que a intervenção cirúrgica é muitas vezes necessária 
para remover tecidos infectados e/ou dispositivos implantados ${ }^{13}$.

\section{Staphylococcus aureus e a coagulação sanguínea}

S. aureus desenvolveu uma estratégia de virulência única que usurpa o sistema hemostático para a sobrevivência e replicação do patógeno em tecidos infectados. Após a entrada na corrente sanguínea, $S$. aureus dissemina-se pelos tecidos do hospedeiro onde poderá iniciar a formação de abscessos, onde a comunidade bacteriana encontra um lugar seguro (salvo do ataque das células imunitárias) para se multiplicar no centro destas lesões graças à pseudocápsula. $O$ crescimento dos abscessos eventualmente ocasiona um rompimento seguido da entrada dos patógenos na circulação sanguínea e propagação para os tecidos não infectados $^{14}$. Uma das estratégias é a secreção de coagulase (COA), um polipeptídeo que se liga e ativa a protrombina, convertendo assim o fibrinogênio em fibrina e promove a coagulação do plasma ou do sangue ${ }^{15}$. Estudos estruturais revelaram que a interação de coagulase e protombina (através da ligação da coagulase a protrombina, por meio dos domínios D1 e D2, e da inserção da porção $\mathrm{N}$ terminal ||$e^{1}-\left.V_{a}\right|^{2}$ da coagulase na posição $\| e^{16}$ de protrombina), induz uma mudança conformacional no sítio ativo do zimogênio. Exosítiol do $\alpha$ trombina, o local de reconhecimento de fibrinogênio, e proexosítio I em protrombina são bloqueados pelo D2 de $\mathrm{COA}^{16}$. No entanto, a associação do complexo tetramérico "(COAProtrombina)2" permite a ligação do fibrinogênio em um novo local com elevada afinidade, justificando a capacidade coagulante e a eficiente conversão de fibrinogénio por COA. O fibrinogênio é uma glicoproteína hexamérica formada por dímeros de

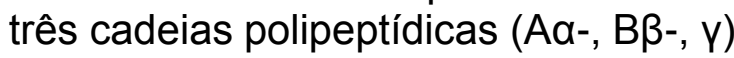
codificada por genes localizados no braço longo do cromossomo 1. As cadeias $A \alpha$ e $B \beta$ são os fibrinopeptídeos liberados pela clivagem da trombina. $O$ complexo COA- Protrombina não é alvo dos inibidores de trombina circulante, permitindo a coagulase contornar a regulação fisiológica das vias de coagulação do sangue ${ }^{17}$.

\section{Terapia anti-virulência}

A virulência é definida como a capacidade relativa de um patógeno causar danos em um hospedeiro. Embora essa definição seja simples, esta associado a uma ampla diversidade de mecanismos, tais como substâncias efetoras de patogenicidade (por exemplo, toxinas), e muitas das funções que não são essenciais para o metabolismo, mas que contribuem para - estabelecimento da infecção ${ }^{9}$. Compostos antivirulência poderiam ter vantagens sobre antibióticos clássicos em duas formas principais: (i) inibindo a expressão de genes-alvo como gtfD, gtfC e gbpB que estão envolvidos com mecanismo de virulência bacteriana, não induzindo pressão seletiva que levaria ao fenômeno de resistência e mutagenicidade; (ii) efeito direcionado contra as bactérias patogênicas, sem causar dano a microbiota residente dos diferentes sítios anatômicos ${ }^{18}$. Estes compostos podem agir inibindo alvos como as coagulases, formação de biofilme, produção de hemolisina e estafiloxantina. Uma revisão compreensiva do tema foi publicada recentemente, mostrando uma variedade de produtos naturais de plantas capazes de inibir a expressão de fatores de virulência ${ }^{19}$. A seguir apresentamos alguns alvos da terapia 
antivirulência e exemplificamos alguns agentes inibidores destas vias.

Estudos demonstram que a ausência de fatores como a COA, diminui a virulência de $S$. aureus, assim como sua capacidade de evadir o ataque das células da imunidade inata ${ }^{20}$. Existem trabalhos que têm aplicado o dabigatrano em modelos de infecções induzidas por $S$. aureus. $O$ dabigatrano é uma molécula sintética que inibe reversivelmente a trombina com alta especificidade e apresenta um favorável perfil farmacocinético ${ }^{21}$. Foi demonstrado que o dabigatrano inibe a atividade das coagulases de $S$. aureus in vitro e in vivo, diminuindo o tamanho do abscesso e a sobrevivência das bactérias ${ }^{22,}{ }^{23}$. Os resultados foram ainda mais promissores quando 0 tratamento com dabigatrano etexilato foi combinado com os anticorpos específicos para $\mathrm{Clf}^{24}$.

Diversos compostos são apontados como inibidores do biofilme de $S$. aureus. Recentemente, um composto natural extraído das folhas de Rhodomyrtus tomentosa (rhodomyrtone) mostrou capacidade de inibir a transcrição de genes relacionados com a formação de biofilme (atL e $i c A)^{25}$. Em outro estudo, o diterpeno Darwinolide foi isolado da esponja Dendrilla membranosa coletada na região da Antártica. Os autores demonstraram que este composto inibiu seletivamente a formação de biofilme de $S$. aureus resistente à meticilina e sugerem que o mesmo pode ser utilizado como molécula líder no desenvolvimento de outros fármacos ${ }^{26}$. Também, foi relatado que 0 efeito de diferentes flavonoides na produção de estafiloxantina para identificar novos agentes antivirulência contra duas linhagens de $S$. aureus. Dentre eles, o composto flavona foi capaz de inibir a estafiloxantina na concentração subinibitória de $50 \mu \mathrm{g} / \mathrm{mL}$. O tratamento com flavona resultou em um aumento de mais de 100 vezes na vulnerabilidade desta bactéria ao peróxido de hidrogênio $\left(\mathrm{H}_{2} \mathrm{O}_{2}\right)$. Em adição, este composto também inibiu a expressão de outros fatores de virulência como a hemolisina, tanto a nível enzimático como a transcrição do gene $h / A$. A transcrição do gene regulador global de virulência $s a E$ também foi afetada. Este estudo demonstrou que a flavona pode ser um agente antivirulência potente contra linhagens de $S$. aureus resistentes a antibióticos ${ }^{27}$.

Do meso modo, outros compostos naturais também possuem a capacidade de inibir a estafiloxantina, como exemplo tem 0 indol e seu derivado 7-benziloxiindol (7BOI). Quando tratado com estes compostos, as colônias de $S$. aureus se mostraram incolores e com reduzida capacidade de resistir ao $\mathrm{H}_{2} \mathrm{O}_{2}$ ou a ação de componentes presentes no sangue. Em adição, 7BOI protegeu o invertebrado Ceanorhabditis elegans da infecção causada por $S$. aureus. Estudos de expressão gênica demonstraram que tanto o indol quanto o 7BOI reprimiram a expressão de diversos genes de virulência como os que codificam para a-hemolisina $(h / A)$, enterotoxina $(s e B)$, e proteases ( $s p / A$ e $s s p A$ ), além dos genes regulatórios (agrA e $\operatorname{sar} A)^{28}$.

\section{Moduladores da resistência a antimicrobianos}

A combinação de antibióticos com produtos naturais tem sido empregada com sucesso em alguns estudos. Existem relatos de susceptibilidade de cepas de Salmonella spp. e Escherichia coli frente à ação combinada de óleo essencial de alecrim com antibióticos (ampicilina, nitrofurantoína e

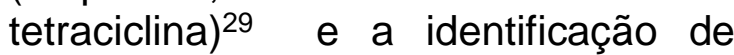
extratos da raiz de Costus cf. arabicus 
como um composto que potencializa a ação da gentamicina, amicacina e neomicina frente $E$. coli, Pseudomonas aeruginosa e $S$. aureus ${ }^{30}$.

Óleos essenciais são bons exemplos de moduladores da atividade antimicrobiana de diversas maneiras. Evidências sugerem que a sinergia entre antibióticos e óleos estaria relacionada com: (i) melhorada difusão dos antibióticos através da membrana bacteriana; (ii) inibição das bombas de efluxo (mecanismo geral de resistência de bactérias); (iii) ação em múltiplos alvos na célula bacteriana ${ }^{31}$. Outros compostos também podem agir aumentando a ação dos fármacos utilizados na clínica. Neste caso a sinergia pode ocorrer quando 0 composto em questão atua em um alvo terapêutico diferente daquele utilizado pela droga convencional ${ }^{32}$.

\section{Terapia imunomoduladora}

Terapias imunomoduladoras são baseadas na melhoria das defesas imunitárias do hospedeiro, em vez de inibir virulência ou a viabilidade do micróbio ${ }^{33},{ }^{34}$. Os microrganismos expressam mecanismos que permitem a colonização ou infecção no hospedeiro e neste contexto, muitos patógenos expressam uma série de estratégias específicas para se estabelecer, colonizar, causar a doença e superar as defesas de hospedeiros susceptíveis $^{35}$. Com isso, estas complexas relações entre efeitos pró e anti-inflamatórios que ocorrem durante a sepse, têm inspirado a pesquisa e desenvolvimento de agentes ativos. Tais estratégias podem contribuir para remoção de fatores imunológicos como o TNF, por exemplo, que se encontram de forma elevada na infecções ${ }^{36}$.

O potencial imunomodulador das lectinas nativa e recombinante de sementes de Cratylia mollis foi avaliado usando macrófagos infectados e não infectados com Staphylococcus aureus. Ambas as lectinas induziram significantemente a produção de óxido nítrico (NO) e de citocinas próinflamatorias (IL-1 $1 \beta$, IL-6, INF-y e TNFa) em macrófagos não infectados. A ação fagocítica dos macrófagos foi aumentada em $27,1 \%$ e $22,47 \%$ após o tratamento destes com pCramoll e rCramoll. Por fim, as lectinas inibiram a expressão de TNF- $\alpha$ e IL-6 e estimularam a produção de IL-1 $1 \beta$ e INFY por macrófagos infectados por $S$. aureus ${ }^{36}$.

Diversos modelos têm sido utilizados na busca de novos agentes imunomoduladores capazes de inibir a capacidade infectiva de $S$. aureus, dentre eles, os que empregam Caenorhabditis elegans (Rhabditidae) têm se destacado ${ }^{37,38}$. Este nematóide terrestre de vida livre é um organismo modelo vantajoso por ser multicelular e apresentar sistemas fisiológicos conservados, tempo de vida curto, devido ao baixo custo de cultivo, facilidade de manipulação genética, genoma completamente sequenciado e cerca de $60-80 \%$ de genes homólogos aos humanos ${ }^{39,40}$. Usando um sistema baseado em $C$. elegans, trinta e sete produtos naturais e 29 compostos sintéticos foram analisados quanto as suas propriedades anti-infectivas. Os compostos selecionados não apresentaram ação antimicrobiana direta. O sistema revelou que 14 produtos naturais de seis plantas (Nypa fruticans, Swietenia macrophylla, Curcuma longa, Eurycoma longifolia, Orthosiphon stamineus e Silybum eburneum) e um amostra marinha (Faunus ater) capazes de melhorar a sobrevivência dos vermes infectados (aproximadamente três vezes). Por outro lado, quatorze compostos sintéticos foram positivos. Estes dados sugerem que estes compostos podem agir tanto inibindo os fatores de 
virulência do patógeno, quanto aumentando as defesas imunológicas do hospedeiro ${ }^{38}$.

\section{Conclusão}

A resistência apresentada por $S$. aureus se tornou um grande problema de saúde pública, onde a sua disseminação pode ter ocorrido através do uso indiscriminado de antibióticos. A busca por novos mecanismos como o uso de compostos naturais e estratégias para combater infecções causadas por esta bactéria é de grande relevância. O estudo abordou a importância do desenvolvimento e implantação de novas terapias antivirulência na qual vem apresentando resultados promissores na inibição dos principais fatores de virulência de $S$. aureus. Esta revisão também retratou como as terapias imunomoduladoras podem resultar no descobrimento e aplicação de novos compostos de grande importância para o combate contras às infecções causadas por $S$. aureus.

\section{Referências}

1. Rodríguez-Rojas, A. et al. Antibiotics and antibiotic resistance: a bitter fight against evolution. International Journal of Medical Microbiology, v. 303, n. 6, p. 293-297, 2013.

2. Lorian V. Medical relevance of low concentrations of antibiotics. J Antimicrob Chemother 1993; 31:137-48.

3. Murray P. R., Baron E.J., Pfaller M. A., Tenover F. C., Yolken R. L. Manual of clinical microbiology. 6th ed. Washington: American Society for Microbiology; 1995.

4. Alanis A. J. Resistance to antibiotics: are we in the post-antibiotic era? Arch MedRes. 2005;36(6):697-705.

5. Mark C. Enright, M., Robinson, A.; Randle, G.; Feil, E.; Grundmann, H.; Spratt, B. The evolutionary history of methicillin-resistat Staphylococcus aureus (MRSA). PNAS, v. 99, p. 7687-7698. 2002.

6. Oliveira D. C., Lencastre H. Multiplex PCR strategy for rapid identification of structural types and variants of the mec element in methicillin-resistant Staphylococcus aureus. Antimicrob Agents Chemother 46: 2155-2161, 2002.

7. Kotsaki A., Giamarellos-Bourboulis E. J. Emerging drugs for the treatment of sepsis. Expert opinion on emerging drugs, v. 17, $\mathrm{n}$. 3, p. 379-391, 2012.

8. Peetermans M., Verhamme P., Vanassche T. Coagulase Activity by Staphylococcus aureus: A Potential Target for Therapy?. In: Seminars in thrombosis and hemostasis. 2015.

9. DENG, S. et al. Bacterial Distribution and Risk Factors of Nosocomial Blood Stream Infection in Neurologic Patients in the Intensive Care Unit. Surg Infect (Larchmt), Sep 19 2018. ISSN 1557-8674.

10. Murray, D. et al. Microbiologia Médica. Elsevier Editora LTDA. p. 176-179. 2014.

11. Chih-Wei L., Yiu-Kay L., Yu-Tsueng L. et al. Staphylococcus aureus Hijacks a skin commensal to intensify its virulence: immunization targeting $\beta$-hemolysin and 
camp factor. The Journal of Investigative Dermatology, 131:401-409. 2011.

12. Holt D. C. et al. A Very Early-Branching Staphylococcus aureus Lineage Lacking the Carotenoid Pigment Staphyloxanthin. Genome Biology and Evolution, 3 881-895. 2011.

13. Lin, M. H. et al. Involvement of Iron in Biofilm Formation by Staphylococcus aureus. PLoS ONE 7:e34388. 2012.

14. Cheng A. G. et al. Genetic requirements for Staphylococcus aureus abscess formation and persistence in host tissues. The FASEB Journal, v. 23, n. 10, p. 3393-3404, 2009.

15. Panizzi $P$. et al. Fibrinogen substrate recognition by staphylocoagulase.(pro) thrombin complexes. Journal of Biological Chemistry, v. 281 , n. 2, p. 1179-1187, 2006.

16. Friedrich R. et al. Staphylocoagulase is a prototype for the mechanism of cofactorinduced zymogen activation. Nature, v. 425, n. 6957, p. 535-539, 2002.

17. Tager M., Drummond M. C. Staphylocoagulase. Annals of the New York Academy of Sciences, v. 128, n. 1, p. 92-111. 1965.

18. Maeda T. et al. Purification and characterization of a serine protease secreted by Brevibacillus sp. $\mathrm{KH} 3$ for reducing waste activated sludge and biofilm formation. Bioresource Technology. V. 102, Issue 22, p 10650-10656. 2011.

19. Silva L. N. et al. Plant Natural Products Targeting Bacterial Virulence Factors. Chemical Reviews, v. 116 , n. 16, p. $9162-$ 9236, 2016.

20. Hair, P. S. et al. Clumping factor. A interaction with complement factor I increases C3b cleavage on the bacterial surface of Staphylococcus aureus and decreases complement-mediated phagocytosis. Infection and immunity, v. 78, n. 4, p. 1717-1727, 2010.

21. Van Ryn, J. et al. The discovery of dabigatranetexilate. Frontiers in pharmacology, v. 4. 2013.
22. Vanassche, T. et al. Dabigatran inhibits Staphylococcus aureus coagulase activity. Journal of clinical microbiology, v. 48, n. 11, p. 4248-4250, 2010.

23. Vanassche, $T$. et al. Inhibition of staphylothrombin by dabigatran reduces Staphylococcus aureus virulence. Journal of Thrombosis and Haemostasis, v. 9, n. 12, p. 2436-2446, 2011.

24. Mcadow, M. et al. Preventing Staphylococcus aureus sepsis through the inhibition of its agglutination in blood. PLoS Pathog, v. 7, n. 10, p. e1002307e1002307, 2011.

25. Saising, J.et al. Inhibition of staphylococcal biofilm-related gene transcription by rhodomyrtone, a new antibacterial agent. Annals of Microbiology, v. 65, n. 2, p. 659-665, 2015.

26. Von Salm et al. Darwinolide, a New Diterpene Scaffold That Inhibits MethicillinResistant Staphylococcus aureus Biofilm from the Antarctic Sponge Dendrilla membranosa. Org. Lett. 18, 11, 25962599, 2016.

27. Lee J. H. et al. Flavone reduces the production of virulence factors, staphyloxanthin and a-hemolysin, in Staphylococcus aureus. Current microbiology, 65(6), 726-732, 2012.

28. Lee J. H. et al. Indole and 7benzyloxyindole attenuate the virulence of Staphylococcus aureus. Applied microbiology and biotechnology, v. 97, n. 10, p. 4543-4552, 2013.

29. Ribeiro, D. S. et al. Avaliação do óleo essencial de alecrim (Rosmarinus officinalis L.) como modulador da resistência bacteriana. Semina: Ciências Agrárias, Londrina, v. 33, n. 2, p. 687-696, abr. 2012.

30. Tintino, S. R., et al. Atividade moduladora de extratos etanólico e hexânico de raiz de Costus cf. arabicus sobre drogas antimicrobianas. R. bras. Bioci., Porto Alegre, v. 11, n. 2, p. 157-162, abr./jun. 2013.

31. Bolla J. M. et al. Strategies for bypassing the membrane barrier in multidrug resistant Gram-negative bacteria. FEBS Letters, v. 585, p. 1682-1690, 2011. 
32. Hemaiswarya S., Kruthiventi, A. K., Doble $M$. Synergism between natural products and antibiotics against infectious diseases. V. 15 P 639-652. 2008.

33. Hancock R. E. W., Nijnik A., Philpott D. J. Modulating immunity as a therapy for bacterial infections. Nature Reviews Microbiology 10, 243-254. 2012.

34. Nijnik A. Immunomodulatory approaches for prevention and treatment of infectious diseases. Current Opinion in Microbiology. V 16, P 590-595. 2013.

35. Naglik J. R., Challacombe J., Hube B. Candida albicans secreted aspartil proteinases in virulence and pathogenesis. Microbiol. Mol. Biol. Rev., Washington, v. 67, n. 3, p. 400-428, 2003.

36. Da Silva L. C. N. et al. Immunomodulatory effects of pCramoll and rCramoll on peritoneal exudate cells (PECs) infected and non-infected with Staphylococcus aureus. International journal of biological macromolecules, v. 72, p. 848-854, 2015.

37. Jakobsen $\mathrm{H}$. et al. The alkaloid compound harmane increases the lifespan of Caenorhabditis elegans during bacterial infection, by modulating the nematode's innate immune response. PLoS One, 2013.

38. Kong C. et al. Discovery of potential antiinfectives against Staphylococcus aureususing a Caenorhabditis elegans infection model. BMC complementary and alternative medicine, v. 14, n. 1, p. 4, 2014.

39. Kaletta T., Hengartner M. O. Finding function in novel targets: $C$. elegans as a model organism. Nature Reviews Drug Discovery, v. 5 , n. 5, p. 387-399, 2006.

40. O'reilly LP. et al. C. elegans in highthroughput drug discovery. Advanced Drug Delivery Reviews, v. 69, p. 247-253, 2014. 